Whaling

\section{Inaccuracies in numbers}

THE difficulty of counting whales accurately has muddied the already turbulent management task of the International Whaling Commission (IWC), whose recent meeting in Bournemouth, Dorset, was the last before a ten-year moratorium on commercial whaling is due to take effect in 1986. The Scientific Committee of IWC will spend that decade on a specific task: researching ways of counting whales and analysing how to incorporate these numbers and their uncertainties into the

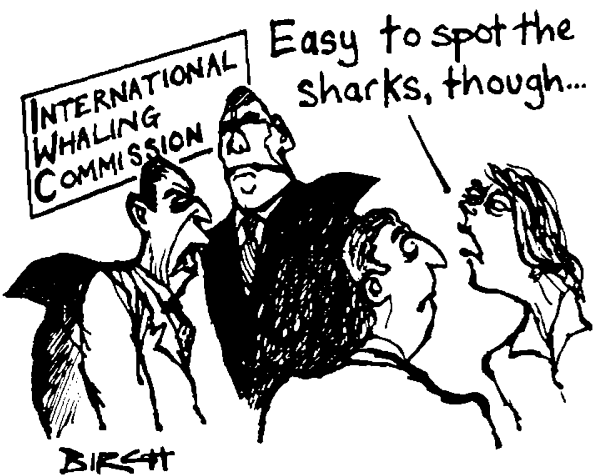

management procedure

Counting whales is not as easy as counting trees or fish. Scientists are confident that the computer models and counting methods used to extrapolate population size and growth trends for trees or fish are accurate - or at least accurate enough to manage the resource. Trees have the comforting habit of standing still, and we know the biology and reproductive rates of fish well enough to predict trends. There is increasing recognition, however, that similar methods applied to whales result in confidence limits so wide that only an extreme change in numbers will register.

Whaling data have traditionally been garnered from the whaling industry itself. A common method has been that of "catch per unit effort", which derived from fisheries work. An index is established from the size of the catch and the amount of effort involved: in other words, if the same effort is involved and a catch is half its former size, the population is half its former size. Sidney Holt, a fisheries biologist now acting as a consultant on marine affairs, is one of many scientists who point to the difficulty of quantifying "effort" and the nonlinear relationship of the index to the actual population size.

Another option is to mark and recapture. Whales are either marked artificially or recognized by their natural marks. If 100 whales are marked or recognized and the next year five of them are recognized again or caught by whalers, the actual population is approximately $20 \times 100$ in size. Individual humpback and right whales, according to Dr Lex Hiby of the Sea Mammal Research Unit, which is supported by the Natural Environment Research Council, are easy to recognize and sometimes extruded. south. blue whales are potentially so because of a lacy pattern on their skin; these species, however, have already been decimated to the point of being protected species. And IWC is having to recognize that artificial marks do not work well for the commercially viable minke and sperm whales. The metal bolts used can kill the whales as they are marked, there is no way to know if a bolt has actually lodged in a whale, and it is now being shown that the bolts are

The sightings method, criss-crossing a given area by plane or ship and estimating the density of whales, is now recognized as offering the best possibilities for an accurate counting model. As at present used, the confidence limits of this method are very wide, says Holt - so wide that a population could be a third of its original size before the change was recognized. The problem is that the method is based on one developed for tree research, which assumes that if a tree is right on the observer's path, it will be seen. Whales, however, dive and travel towards and away from the observer, which means there is no assurance that whales right on the path will be counted accurately. The Sea Mammal Research Unit is part of an international effort to control variability

\section{French research}

\section{Southern festival of science}

WHY not take in a laboratory or two on the way south to the Côte d'Azur? Until 18 August, the leading French research council (the Centre National de la Recherche Scientifique) is running a kind of continuous science festival at three of its laboratories in the south of France. The project is the successor to a major CNRS achievement last year, when it took over 2,000 square metres of space under the Eiffel Tower in Paris for 2 weeks for an exhibition on all aspects of communication, from technology to languages and involving journalists, actors and a variety of forms of presentation. Some 10,000 visitors attended, and M. Goéry Delacotte, CNRS director of information, is hoping for a similar success in the south.

"People are always asking us what we have discovered with their money", says Delacotte, and with these exhibitions CNRS is setting out to reply - and, no doubt, to win friends and influence people. It has set up a full-time "exploration workshop" in Meudon, near Paris, with a model-making staff of 10 . Some of the results are in use at the new festival in the

Delacotte is particularly proud of a lens designed to show the precise gravitational lensing of a quasar by a nearby galaxy, separating the quasar light into three in sightings counts, running such experiments in the Antarctic as counting whales from ships moving in parallel or counting whale blows per unit area per unit time.

The scientific committee's review of the data gathered during the moratorium, as well as of research priorities and survey methods, is intended to establish more accurate guidelines for gauging the impact of whaling. If the effort fails, says Dr John Harwood, head of the Sea Mammal Research Unit, it will be a "sad reflection on science and management". It will also in part determine whether Mr John MacGregor, Minister of Agriculture, Fisheries and Food, was right in calling the moratorium "a landmark in the long history of man's relationship with these most fascinating creatures of the sea".

But whether there really will be a lapse in commercial whaling depends on such factors as US pressure on Japan and whether South Korea and Iceland do in fact kill over 200 whales each per year for "scientific research". Even if IWC had real teeth and enough money, the world's oceans are such a huge area to monitor that the success of the moratorium is dependent on the cooperation of the countries that have the most to gain by ignoring it. Luckily some species of whale, notably the blue, will receive added protection under an international convention to protect threatened migratory animals, which Britain signed last week. Elizabeth Collins

different images. That is on display at the 13-telescope Observatoire de Haute Provence, near St Michel. Also on show are atmospheric studies by LIDAR, work in interacting galaxies (the Magellanic Clouds) and studies of Halley's comet (in which the observatory is closely involved), all with mock-ups and exhibits.

Other sites involved are the solar energy laboratory at Odeilla-Font-Romeu (in the east Pyrenees) and a group of marine laboratories at Villefranche-sur-mer. At all these exhibition sites there are regular lectures, exhibitions and activities for children.

What is more, visitors will also find real scientists of whom to ask questions, it now being an official duty of a French scientist, and one which can in principle advance his or her career, to popularize science.

CNRS is spending some FF 2 million $(£ 160,000)$ per site for the festival, Delacotte estimates. If this year's trial is successful, the exercise may spread to cover the whole of France. "It's important to reach a critical mass", Delacotte says

Robert Walgate

For more information on addresses and opening times, contact the Direction de I'Information Scientifique et Technique, CNRS, 15 quai Anatole France, 75700 Paris, or telephone Paris 5559225 